\title{
CONFORTO ACÚSTICO EM UM DOMICÍLIO URBANO - ESTUDO DE CASO
}

Leonardo Lã Ferrari ${ }^{1}$

Stéphanie Lã Ferrari²

Jéferson Luiz Ferrari ${ }^{3}$

Resumo: Este trabalho teve como objetivo avaliar as condições de conforto acústico em uma residência da zona urbana do município de Alegre, estado do Espírito Santo, Brasil. As medições foram realizadas em dois horários: às $5 \mathrm{~h}$ da manhã e às 3 da tarde (15 h). Foi empregado um decibelímetro digital e o método de avaliação foi baseado nas medições do nível sonoro dos compartimentos da residência, em comparação com os níveis de ruído para conforto acústico (NBR 10.152/1987) e com ruídos máximos toleráveis em áreas habitadas (NBR 10.151/2000). Os valores de decibéis (dB) dos dormitórios variaram de 18 a $50 \mathrm{~dB}$, enquanto que os valores de $d B$ das salas variaram de 18 a 63. O único compartimento da casa que apresentou o nível de ruído constante, acima do preconizado pelas normas, foi a cozinha. Fenômeno este ocorrido apenas às $17 \mathrm{~h}$.

Palavras-chave: Ambiência acústica; Conforto ambiental; Bem-Estar; Paisagem sonora.

\footnotetext{
${ }^{1}$ Aluno do Curso Técnico em Agropecuária/IFES-Campus de Alegre, Brasil. E-mail: ferrarileo14@hotmail.com.

2 Graduanda do Curso de Direito/Faculdade de Direito de Cachoeiro de Itapemirim, Brasil. E-mail: laferrari.stephanie@gmail.com.

${ }^{3}$ Professor Orientador/IFES-Campus de Alegre, Brasil. E-mail: ferrarijluiz@gmail.com.
} 